\title{
Discovery and Characterization of Catalysts for Azide-Alkyne Cycloaddition by Fluorescence Quenching
}

\author{
Warren G. Lewis, Fernando G. Magallon, Valery V. Fokin, and M.G. Finn* \\ Department of Chemistry and The Skaggs Institute for Chemical Biology \\ The Scripps Research Institute, 10550 N. Torrey Pines Rd., La Jolla, CA 92037

\section{Supporting Information}

\author{
A. Additional references to catalysis screening by fluorescence methods. \\ Reviews: \\ Loch, J.A.; Crabtree, R.H. Pure Appl. Chem. 2001, 73, 119-128 \\ Crabtree, R.H. Chem. Commun. 1999, 1611-1616 \\ Dansyl/diazo quenching in organic solution for cross-coupling catalysis \\ Stambuli, J. P.; Hartwig, J. F. Curr. Opin. Chem. Biol. 2003, 7, 420-426 \\ Stauffer, S. R.; Hartwig, J. F. J. Am. Chem. Soc. 2003, 125, 6977-6985 \\ Shaughnessy, K. H.; Kim, P.; Hartwig, J. F. J. Am. Chem. Soc. 1999, 121, 2123-2132. \\ Fluorogenic substrates \\ Pope, A.J.; Haupts, U.M.; Moore, K.J. Drug Disc. Today 1999, 4, 350-362 \\ List, B.; Barbas III, C.F.; Lerner, R.A. Proc. Nat. Acad. Sci. USA 1998, 95, 15351-15355. \\ Dye-bleaching assays \\ Cooper, A.C.; McAlexander, L.H.; Lee, D.-H.; Torres, M.T.; Crabtree, R.H. J. Am. Chem. Soc. \\ 1998, 120, 9971-9972. \\ Fluorogenic $\mathrm{pH}$ indicators \\ Copeland, G.T.; Miller, S.J. J. Am. Chem. Soc. 1999, 121, 4306-4307. \\ Evans, C.A.; Miller, S.J. Curr. Opin. Chem. Biol. 2002, 6, 333-338. \\ Solid-phase fluorophores \\ Hoveyda, A.H. Chem. Biol. 1999, 6, R305-R308.
}

\section{B. General Remarks}

Safety. Sodium azide is toxic, and the extremely hazardous hydrazoic acid (volatile, toxic, explosive) is generated in contact with acids. Many organic azides with a saturated carbon:azide ratio of $<6$ (such as azidopropylamine) may be heat and shock sensitive, and should not be handled neat. Phenylenediamine and phenylacetylene are suspected cancercausing agents. Propargylamine is toxic. Dimethyl sulfoxide can pass through gloves and skin. Due caution should be exercised with these compounds.

General. Dansyl chloride, 3-bromopropylamine hydrobromide, and other reagents were obtained from Acros Organics/Fisher Chemical unless otherwise stated. Dabsyl chloride and propargylamine were purchased from Fluka. Benzyl azide was obtained from Alfa, or synthesized from benzyl bromide and sodium azide. Sulfonated bathophenanthroline was purchased from GFS Chemicals. Eppendorf pipetters were used.

\author{
Abbreviations \\ DMSO Dimethyl sulfoxide \\ Dabsyl Dimethylaminobenzenesulfonyl \\ Dansyl Dimethylaminonaphthalenesulfonyl \\ Tris tris(hydroxymethyl) aminomethane \\ TLC thin layer chromatography on silica gel
}




\section{Experimental Details}

1. Synthesis. The fluorophore and quenchers were prepared from commercially available sulfonyl chlorides (Figure S1).

Figure S1. Synthesis of compounds 1, 2, and 4.

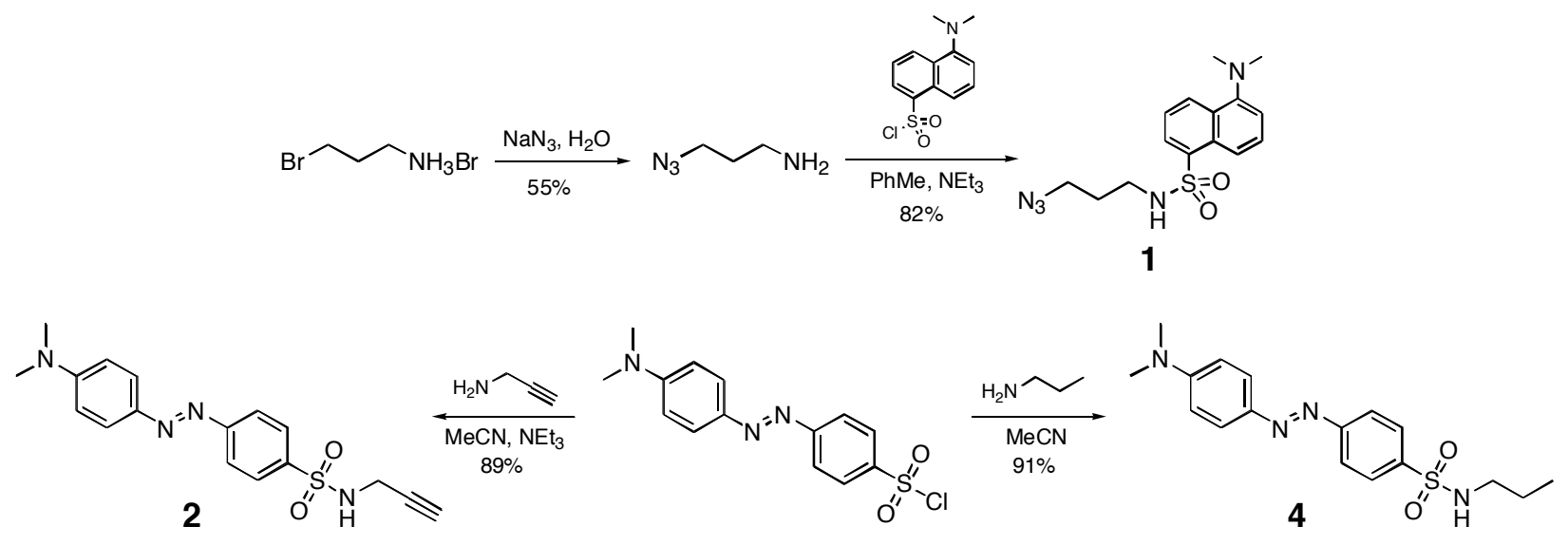

3-Azidopropylamine. 3-bromopropylamine hydrobromide $(9.76 \mathrm{~g}, 44.6 \mathrm{mmol})$ and sodium azide $(5.0 \mathrm{~g}, 77 \mathrm{mmol}, 1.7$ equiv) were dissolved in water $(80 \mathrm{~mL})$. The flask was fitted with a water condenser and heated to $80^{*} \mathrm{C}$ (monitored by a thermometer in the reaction mixture) with stirring for $15 \mathrm{~h}$. The resulting mixture was reduced by rotary evaporation with gentle heating $\left(\sim 50^{\circ} \mathrm{C}\right)$ to about $30 \mathrm{~mL}$ volume, not to dryness, after which $5 \%$ aqueous $\mathrm{NaOH}(18 \mathrm{~mL})$ was added. The mixture was stirred for several hours and then extracted with toluene $(2 \times 25 \mathrm{~mL})$. An additional $40 \mathrm{~mL}$ of $5 \%$ aqueous $\mathrm{NaOH}$ was added to the aqueous phase $(\mathrm{pH}=11)$, and four additional extractions were done with toluene $(25 \mathrm{~mL}$ each). The combined organic layers were dried with $\mathrm{Na}_{2} \mathrm{SO}_{4}$ and filtered. The volume was then reduced by rotary evaporation with mild heating $\left(\sim 40^{\circ} \mathrm{C}\right)$ to $49 \mathrm{~g}$ of solution, and some of the desired product was also detected in the distillate, which was discarded. The retained solution was found to contain $4.6 \mathrm{~mol} \%$ of 3azidopropylamine NMR integration, corresponding to $5.0 \%$ by weight $(2.44 \mathrm{~g})$ of the desired product $(55 \%$ yield $) .{ }^{1} \mathrm{H}$ NMR $\left(200 \mathrm{MHz} \mathrm{CDCl}_{3}, \delta\right) 3.57(2 \mathrm{H}, \mathrm{t}, \mathrm{J}=8.4,6.7 \mathrm{~Hz}), 3.03(2 \mathrm{H}, \mathrm{t}, 6.7$ $\mathrm{Hz}), 1.95(2 \mathrm{H}, \mathrm{m}), 1.35(2 \mathrm{H}, \mathrm{br} \mathrm{s})$.

5-Dimethylamino-naphthalene-1-sulfonic acid (3-azidopropyl) amide (dansyl azide 1). A solution of triethylamine $(1.2 \mathrm{~g}, 12 \mathrm{mmol})$ and 3-azido-propylamine $(500 \mathrm{mg}, 5 \mathrm{mmol})$ in $9.5 \mathrm{~g}$ toluene was added all at once to a stirred suspension of dansyl chloride $(1.56 \mathrm{~g}, 5.8 \mathrm{mmol})$ in 30 $\mathrm{mL}$ toluene. The solution became homogeneous and was stirred at room temperature overnight. The solvent was removed in vacuo to leave a yellow residue, which was purified by chromatography over a short silica column, eluting with 4:1 EtOAc/MeCN. Compound 1 was isolated as a viscous yellow oil $(1.59 \mathrm{~g}, 82 \%)$. The product has an $R_{f}$ value of 0.3 in $3: 1$ hexanes/EtOAc, and its yellow-green fluorescence is clearly visible. A very small amount of blue fluorescent hydrolysis product was present before purification. Note: The compound has a tendency to streak on the chromatography column. Alumina may also be used. ${ }^{1} \mathrm{H}$ NMR $(200$ $\left.\mathrm{MHz}, \mathrm{CDCl}_{3}, \delta\right) 8.59(1 \mathrm{H}, \mathrm{d}, J=8.2 \mathrm{~Hz}), 8.28(2 \mathrm{H}, \mathrm{m}), 7.57(2 \mathrm{H}, \mathrm{m}), 7.24(1 \mathrm{H}, \mathrm{m}), 4.9(1 \mathrm{H}$, broad $\mathrm{m}), 3.28(2 \mathrm{H}, \mathrm{td}, J=6.5,3.1 \mathrm{~Hz}), 3.00(2 \mathrm{H}, \mathrm{qd}, J=6.2,3.6 \mathrm{~Hz}), 2.93(3 \mathrm{H}, \mathrm{s}), 2.91(3 \mathrm{H}, \mathrm{s})$ and $1.66(2 \mathrm{H}$, dd, 6.5, $3.2 \mathrm{~Hz})$.

4-(4-Dimethylamino-phenylazo)-N-prop-2-ynyl benzenesulfonamide (dabsyl alkyne 2) Dabsyl chloride (499 mg, $1.54 \mathrm{mmol}$ ) was suspended in $15 \mathrm{~mL}$ acetonitrile, and the suspension was 
stirred while the vessel was purged with nitrogen. Triethylamine $(320 \mu \mathrm{L})$ was added by syringe, followed by $110 \mu \mathrm{L}$ propargylamine. After stirring overnight under nitrogen, $100 \mathrm{~mL}$ chloroform was added. The resulting solution was washed with $100 \mathrm{~mL}$ water, $50 \mathrm{~mL}$ saturated $\mathrm{NaHCO}_{3}$, then $50 \mathrm{~mL}$ brine. The organic solution was dried over $\mathrm{Na}_{2} \mathrm{SO}_{4}$ and evaporated to afford 2 as a red crystalline solid (472 mg, 89\%). ${ }^{1} \mathrm{H}$ NMR $\left(200 \mathrm{MHz}, \mathrm{CDCl}_{3}\right) \delta=7.96(6 \mathrm{H}, \mathrm{m}), 6.76(2 \mathrm{H}, \mathrm{d}, J$ $=9.1 \mathrm{~Hz}), 4.63(1 \mathrm{H}, \mathrm{t}, J=6.1 \mathrm{~Hz}) 2.74(2 \mathrm{H}, \mathrm{dd}, J=6.1,2.2 \mathrm{~Hz}), 3.12(6 \mathrm{H}, \mathrm{s}), 2.10(3 \mathrm{H}, \mathrm{t}, J=2.2$ $\mathrm{Hz}) .{ }^{13} \mathrm{C}$ NMR $\left(200 \mathrm{MHz}, \mathrm{DMSO}-d_{6}\right) \delta=154.4,152.9,142.4,140.1,127.9,125.2,121.9,111.5$, 79.1, 74.7, 31.8.

4-(4-Dimethylamino-phenylazo)-N-propyl-benzenesulfonamide (unreactive quencher 4 ) To dabsyl chloride (653 mg, $2 \mathrm{mmol}$ ) in $20 \mathrm{~mL}$ dry acetonitrile was added $400 \mu \mathrm{L}$ propylamine. The reaction was stirred overnight, and the solvent was removed by evaporation. Dichloromethane $(50 \mathrm{~mL})$ was added to the residue, followed by $50 \mathrm{~mL}$ water. After stirring for a few hours, an additional $25 \mathrm{~mL}$ of $\mathrm{CH}_{2} \mathrm{Cl}_{2}$ was added, and the layers were separated. The organic layer was dried with $\mathrm{Na}_{2} \mathrm{SO}_{4}$ and evaporated to give 4 as a red crystalline solid $\left(637 \mathrm{mg}, 91 \%\right.$ yield). ${ }^{1} \mathrm{H}$ $\operatorname{NMR}\left(200 \mathrm{MHz}, \mathrm{CDCl}_{3}\right) \delta 7.91(4 \mathrm{H}, \mathrm{s}), 7.83(2 \mathrm{H}, \mathrm{d}, J=8.2 \mathrm{~Hz}), 7.66(1 \mathrm{H}, \mathrm{t}, 5.7 \mathrm{~Hz}), 6.86(2 \mathrm{H}, \mathrm{d}$, $8.4 \mathrm{~Hz}), 3.09(6 \mathrm{H}, \mathrm{s}), 2.74(2 \mathrm{H}, \mathrm{q}, 6.6 \mathrm{~Hz}), 1.38(2 \mathrm{H}, \mathrm{m}), 0.79(3 \mathrm{H}, \mathrm{t}, 7.3 \mathrm{~Hz}).) .{ }^{13} \mathrm{C} \mathrm{NMR}(200$ $\left.\mathrm{MHz}, \mathrm{DMSO}-d_{6}\right) \delta=154.3,153.0,142.5,140.4,127.7,125.3,122.1,111.5,44.3,22.4,11.1$.

Cycloaddition product (3). In a $500 \mathrm{~mL}$ round-bottomed flask, compounds 1 ( $200 \mathrm{mg}, 0.6 \mathrm{mmol})$ and 2 (206 mg, $0.6 \mathrm{mmol}$ ) were dissolved in $60 \mathrm{~mL}$ DMSO. Water $(30 \mathrm{~mL})$ was added, followed by aqueous sodium ascorbate $(0.2 \mathrm{~mL}$ of $1 \mathrm{M}$ stock solution) and aqueous copper sulfate $(0.6$ $\mathrm{mL}$ of $100 \mathrm{mM}$ stock solution). The reaction was followed by TLC, eluting with 1:1 hexanes:EtOAc. After stirring overnight, the reaction was found to be complete, and $125 \mathrm{~mL}$ water was added to precipitate the product. After standing open to air for several hours, the orange solid was filtered and washed with water. The product was divided finely and thoroughly dried to give $330 \mathrm{mg}$ of the triazole $(81 \%)$. ${ }^{1} \mathrm{H}$ NMR $(200 \mathrm{MHz}$, DMSO-d-6 with MeOD) $\delta 8.44$ $(1 \mathrm{H}, \mathrm{d}, \mathrm{J}=8.9), 8.26(1 \mathrm{H}, \mathrm{d}, \mathrm{J}=9.1), 8.05(1 \mathrm{H}, \mathrm{d}, 7.1), 7.81(6 \mathrm{H}, \mathrm{m}), 7.55(3 \mathrm{H}, \mathrm{m}), 7.21(1 \mathrm{H}, \mathrm{d}, 7.3$ $\mathrm{Hz}), 6.79(2 \mathrm{H}, \mathrm{d}, 9.0 \mathrm{~Hz}), 4.19(2 \mathrm{H}, \mathrm{t}, 6.5), 4.06(2 \mathrm{H}, \mathrm{m}), 3.06(6 \mathrm{H}, \mathrm{s}), 2.79(6 \mathrm{H}, \mathrm{s}), 2.69(2 \mathrm{H}, \mathrm{t}$, $7), 1.74(2 \mathrm{H}, \mathrm{m})$. Note: without the addition of MeOD, the sulfonamide signals shift into the aromatic region and complicate the spectrum. The signals at 4.19 and $4.06 \mathrm{ppm}$ were not visible in the presence of MeOD, being obscured by the residual protic solvent peak, and were therefore obtained from the spectrum in pure DMSO- $d_{6}$.

Representative preparative-scale Schiff base formation ( $N, N$-Dimethyl- $N$ '-pyridin-2-ylmethylenepropane-1,3-diamine). To a nitrogen-purged round bottomed flask containing $5.3 \mathrm{~g}$ (50 mmol) anhydrous sodium carbonate in $30 \mathrm{~mL}$ absolute ethanol was added $1.26 \mathrm{~mL}$ 3-dimethylamino propylamine followed by $0.96 \mathrm{~mL}$ 2-pyridine carboxaldehyde. After three days of stirring, the mixture was filtered and ethanol was removed in vacuo, giving $1.92 \mathrm{~g}$ (quant.) of the Schiff base ${ }^{1} \mathrm{H}$ NMR $\left(200 \mathrm{MHz}, \mathrm{CDCl}_{3}\right) \delta=8.65(1 \mathrm{H}, \mathrm{m}), 8.40(1 \mathrm{H}, \mathrm{s}), 8.01(1 \mathrm{H}, \mathrm{dd}, J=8.0,0.8 \mathrm{~Hz}), 7.75$ $(1 \mathrm{H}, \mathrm{t}, J=7.4 \mathrm{~Hz}), 7.32(1 \mathrm{H}, \mathrm{m}), 3.72(2 \mathrm{H}, \mathrm{td}, J=7.0,1.2 \mathrm{~Hz}), 2.37(2 \mathrm{H}, \mathrm{t}, J=7 \mathrm{~Hz}), 2.24(6 \mathrm{H}$, s), $1.90(2 \mathrm{H}, \mathrm{m}, J=7.0 \mathrm{~Hz})$.

\section{Low-Stringency Screening for Cycloaddition Catalysts.}

UV-transparent 96 well plates were used, and images were obtained using an Alphaimager, under long wave UV irradiation from the bottom with exposure times of 1/15 $2 / 15 \mathrm{~s}$. For convenience, multichannel pipetters were used to add and dilute reagents, except ligands, which were added with repeater pipetters. Note: All reported reactions were performed below approximately $2 \mathrm{mM}$ in $\mathrm{Cu}$ to eliminate problems of solubility and quenching observed in trials at higher concentrations. The reaction proceeded with mid-micromolar concentrations of 
substrates to provide non-saturating levels of fluorescence so that the reactions could be directly monitored without removing aliquots.

A gradient of copper concentrations was generated by two-fold serial dilutions from a stock solution of aqueous copper sulfate $(1-10 \mathrm{mM}$, depending on the experiment). $50 \mu \mathrm{L}$ of fluorophore solution $(1,200 \mu \mathrm{M}$ in DMSO) was added to each well. To the active test rows (A-D) were added $50 \mu \mathrm{L}$ of dabsyl alkyne $(2,200 \mu \mathrm{M}$ in DMSO). The control rows (E-H) were treated with the same amount of unreactive quencher 4 . All wells were treated with $50 \mu \mathrm{L}$ tris- $\mathrm{HCl}$ buffer $(0.5 \mathrm{M}$ at $\mathrm{pH} 7.5)$. The candidate ligand was then added to rows $A-D$, generally as a $10 \mathrm{mM}$ solution in DMSO; more stringent screens used the same procedure but with $1 \mathrm{mM}$ or $0.1 \mathrm{mM}$ ligand solutions. The control reactions used DMSO in place of the ligand solution.

Reactions were initiated by the addition of $50 \mu \mathrm{L}$ of $100 \mathrm{mM}$ sodium ascorbate. Immediately after this addition, the pipetter was set to $100 \mu \mathrm{L}$ and the wells were mixed by carefully pipetting up and down. This process took approximately two minutes. The amounts of materials are summarized in tables accompanying each figure.

An example of the screening method is shown in Figure S2, highlighting the importance of the negative control using $\mathbf{4}$ in place of $\mathbf{2}$. Note that $\mathbf{C}, \mathbf{E}, \mathbf{F}$, and $\mathbf{G}$ may be active catalysts, but at this concentration, the fluorescence is at least partially quenched in the absence of azidealkyne addition reaction (indicated by the fact that wells containing the unreactive quencher control are darker than the "no ligand" wells). Figure S3 shows screening under conditions of more dilute ligand and at shorter reaction time, in order to reveal the differences between bipytype, and tris(triazolylamine) systems.

Figure S2. An example of the visual fluorescence quenching screen at 13 minutes reaction time.

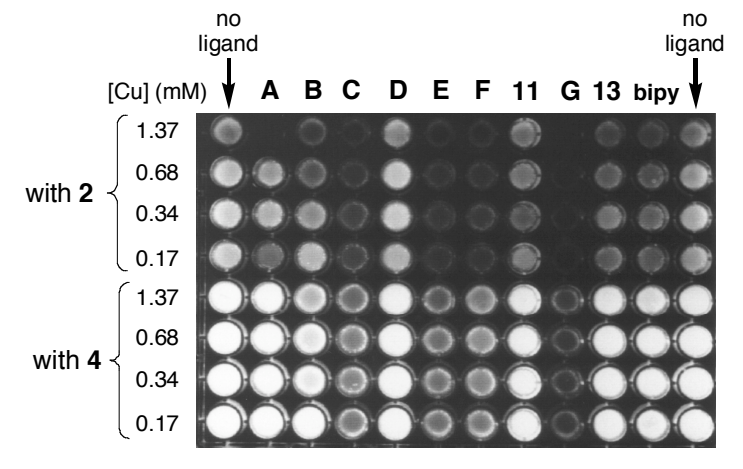

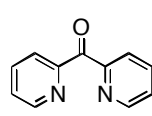

A<smiles>c1cc(-c2cc[nH]c2)c[nH]1</smiles>

B

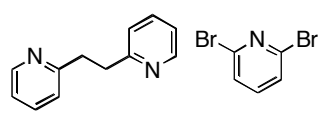

C

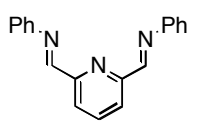

G

D<smiles>C1=CN=C(N=C2C=CN=C2c2ccc[nH]2)C1</smiles><smiles></smiles><smiles>Cc1ccnc(-c2cc(C)ccn2)c1</smiles>

13

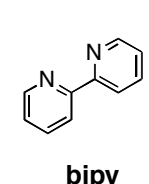

Table S1. Reagents employed in screens of the type shown in Figure S2.

\begin{tabular}{|c|c|c|c|c|c|c|}
\hline & $\mathbf{1}$ & $\mathbf{2}$ or $\mathbf{4}$ & $\mathrm{CuSO}_{4}$ & Tris & lig in DMSO & Na ascorbate \\
\hline amount $(\mu \mathrm{L})$ & 50 & 50 & 100 & 50 & 20 & 50 \\
\hline stock conc. $(\mathrm{mM})$ & 0.2 & 0.2 & varies & 500 & 0.1 & 100 \\
\hline final $(\mathrm{mM})$ & 0.031 & 0.031 & varies & 78.13 & 0.00625 & 15.63 \\
\hline
\end{tabular}

volume $=320 \mu \mathrm{L}, 38 \%$ DMSO, 62\% Tris buffer $(\mathrm{pH} 7.5)$ 
Figure S3. Screening under more stringent conditions: [ligands] $=16$ $\mu \mathrm{M}, 4$ min reaction time, otherwise as in Figure S2.

Ligand $\mathbf{H}$ was kindly provided by Mr. Timothy Chan.
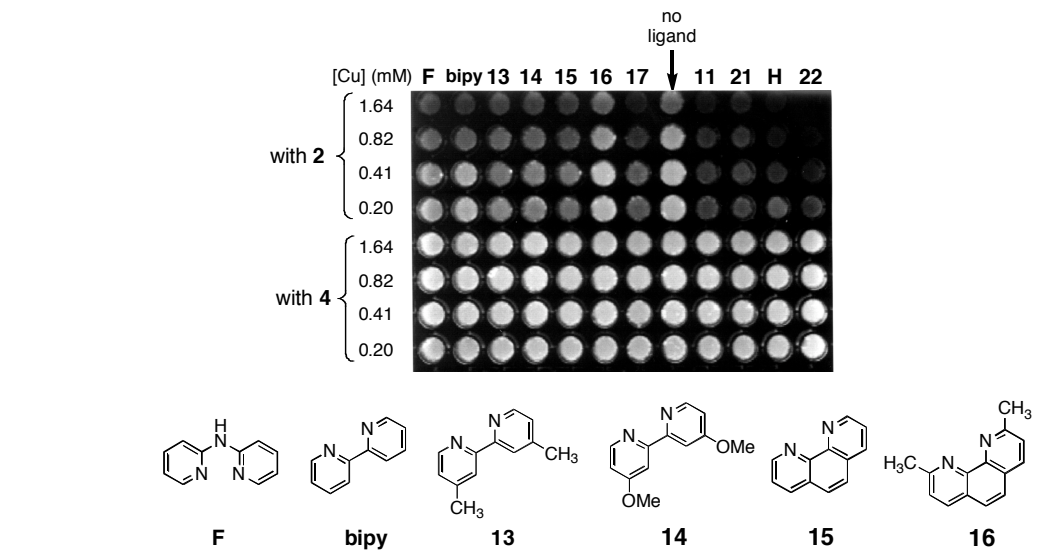

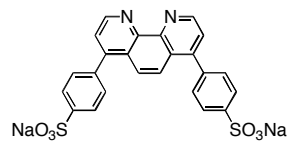

17

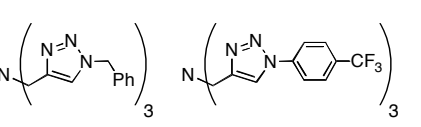

21

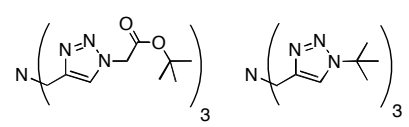

H
22

Table S2. Reagents employed in screens of the type shown in Figure S3.

\begin{tabular}{|c|c|c|c|c|c|c|}
\hline & $\mathbf{1}$ & $\mathbf{2}$ or $\mathbf{4}$ & $\mathrm{CuSO}_{4}$ & Tris & lig in DMSO & Na ascorbate \\
\hline amount $(\mu \mathrm{L})$ & 50 & 50 & 100 & 50 & 5 & 50 \\
\hline stock conc. $(\mathrm{mM})$ & 0.2 & 0.2 & varies & 500 & 1 & 100 \\
\hline final $(\mathrm{mM})$ & 0.033 & 0.033 & varies & 82.0 & 0.016 & 16.4 \\
\hline
\end{tabular}

volume $=305 \mu \mathrm{L}, 34 \%$ DMSO, 66\% Tris buffer $(\mathrm{pH} 7.5)$

\section{Construction and analysis of Schiff base ligand libraries}

A Schiff base library was constructed from the commercially-available aldehydes and amines shown in Chart S1. The crude amine-aldehyde reaction mixtures were generally quite clean, and initial screening was performed without purification. Subsequent tests showed that whenever the imines were purified, they behaved identically to the unpurified library samples. The library was tested using a constant concentration of $\mathrm{Cu}(0.28 \mathrm{mM})$ and showed pyridinecontaining Schiff bases to be promising. Control runs using unreactive quencher 4 demonstrated that mixtures containing aldehydes $23,25,26$, and 30 caused degradation of the fluorophore, presumably by an oxidative or radical pathway, invalidating the apparent hits with 23 and 30. Indeed, salicylimine copper $(\mathrm{I})$ complexes under illumination, ${ }^{1}$ as well as copperamino acid transition metal complexes in the presence of ascorbate, ${ }^{2}$ have been reported to cleave DNA by radical mechanisms. Use of dithionite, tris(carboxyethyl)phosphine, or hydrazine as reducing agents instead of ascorbate gave spurious results and loss of orange color, apparently because of reaction with the quencher's diazo functionality.

1. Dhar, S.; Senapati, D.; Das, P. K.; Chattopadhyay, P.; Nethaji, M.; Chakravarty, A. R. J. Am. Chem. Soc. 2003, 125, 1211812124. 


\section{Chart S1}

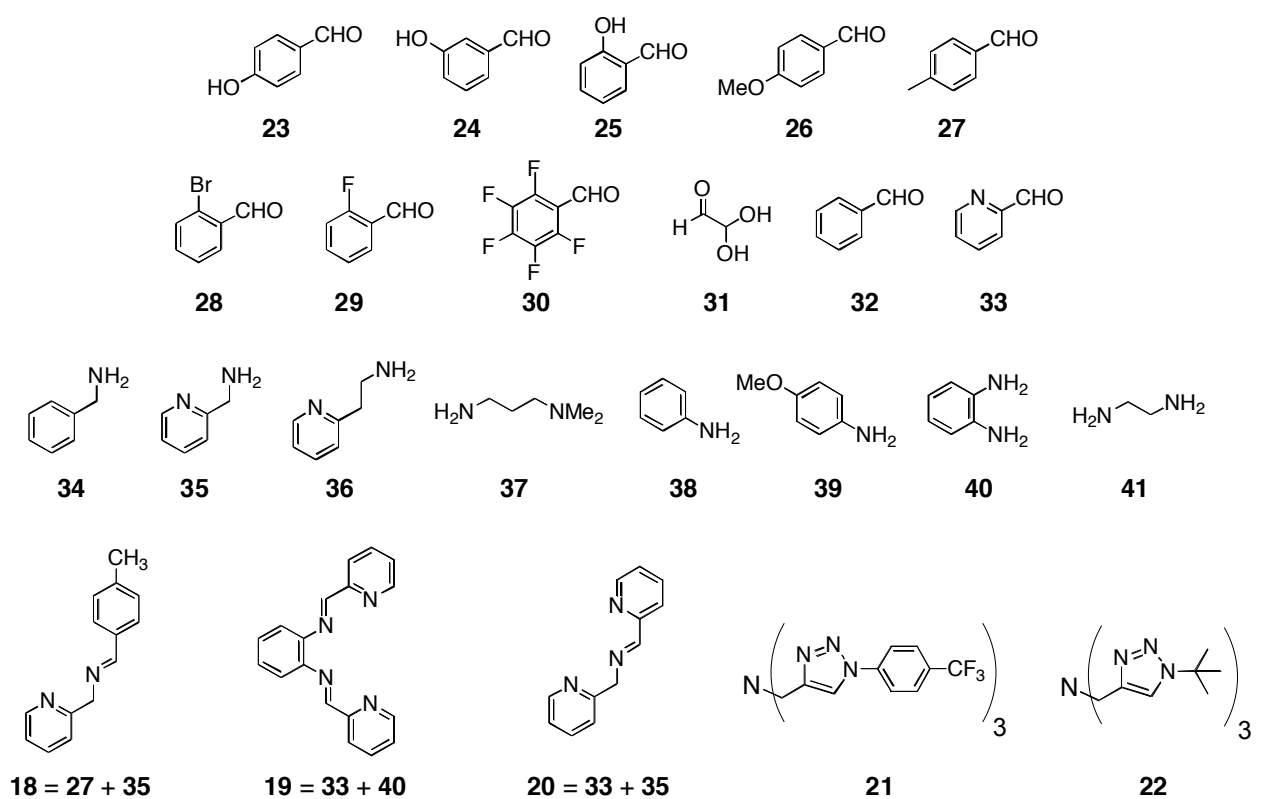

General procedure. $1 \mathrm{M}$ stock solutions of monofunctional aldehydes and amines (or $0.5 \mathrm{M}$ solutions for bifunctional compounds) in absolute ethanol were prepared. Sodium carbonate (> 5 equiv with respect to aldehyde) was placed as a solid in each well of a deep-well polypropylene 96 -well plate. $400 \mu \mathrm{L}$ of amine and aldehyde stock solutions were then added, the plate was sealed with a mat, and the mixtures were shaken on an orbital shaker for three days. The resulting mixtures were diluted $100 x$ into absolute ethanol to make $5 \mathrm{mM}$ stocks $(2.5$ $\mathrm{mM}$ for bifunctional compounds) in a microtiter plate.

The resulting ligand solutions were introduced using a multichannel pipetter to a plate containing fluorophore, quencher, and copper sulfate. Sodium ascorbate was then added, the wells were mixed as described above, and the plate was imaged after 5-20 minutes. The compositions of the reaction solutions are summarized in Table S2, and a typical example of a reaction plate under long-wavelength UV illumination is shown in Figure S4.

Table S3. Composition of reactions involving Schiff base ligands, visually screened in microtiter plates, as shown in Figure S4.

\begin{tabular}{|c|c|c|c|c|c|c|}
\hline & 1 & 2 or 4 & $\mathrm{CuSO}_{4}$ & Tris & lig in EtOH & Na ascorbate \\
\hline amount $(\mu \mathrm{L})$ & 50 & 50 & 100 & 50 & 10 & 50 \\
\hline stock conc $(\mathrm{mM})$ & 0.2 & 0.2 & 1 & 500 & 5 & 100 \\
\hline final conc. $(\mathrm{mM})$ & 0.032 & 0.032 & 0.32 & 80.6 & 0.16 & 16 \\
\hline
\end{tabular}

volume $=310 \mu \mathrm{L}, 32 \% \mathrm{DMSO}, 65 \%$ Tris buffer $(\mathrm{pH} 7.5), 3 \% \mathrm{EtOH}$ 
Figure S4. Top:

fluorescence imaging of test reactions involving Schiff bases made from the indicated components. Boxed wells indicate effective catalysis. For all reactions, $\left[\mathrm{CuSO}_{4}\right]=0.28 \mathrm{mM}$, [ligand $]=$ $0.14 \mathrm{mM}$, [Na ascorbate] $=14$ $\mathrm{mM},[1]=[2]=29 \mu \mathrm{M}$, reaction time $=15 \mathrm{~min}$.

Bottom: Unreactive quencher control (4 instead of 2).

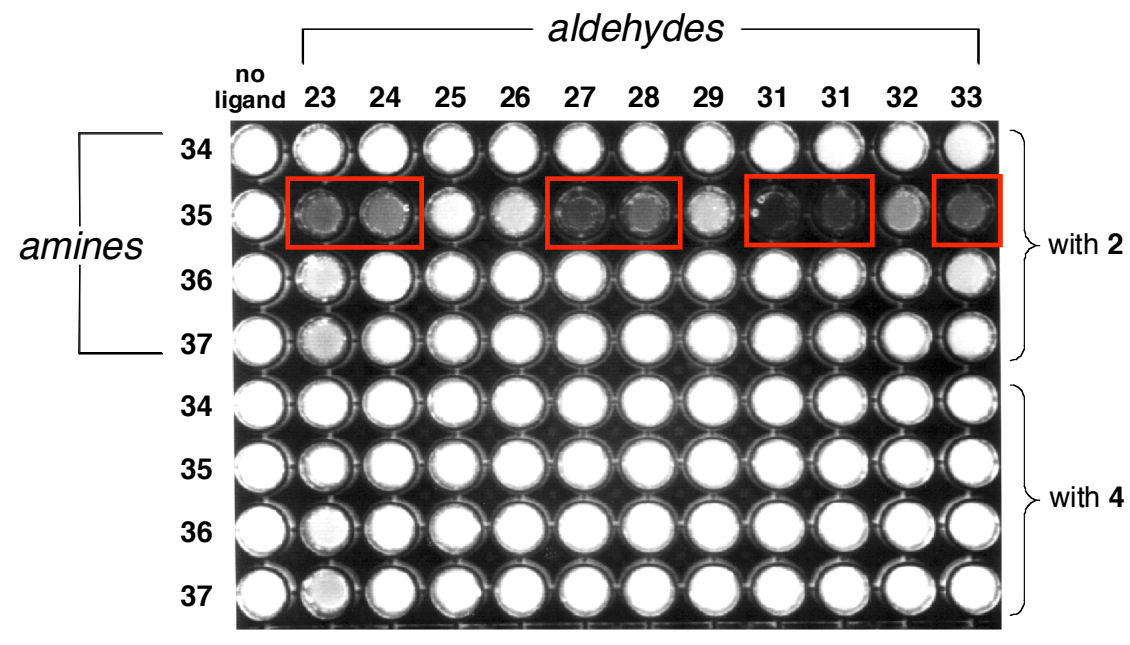

4. Kinetic Analysis. Continuous monitoring of reactions was performed on a Molecular Devices Spectramax Gemini fluorescence plate reader using the following settings:

\begin{tabular}{|l|l|l|}
\hline Reads/well: 15 & Interval: $2-5 \mathrm{~min}$ & Time: several hours \\
\hline PMT Sensitivity: High & Excitation: $320 \mathrm{~nm}$ & Emission: $538 \mathrm{~nm}$ \\
\hline Filter: $420 \mathrm{~nm}$ & Mixing: $15 \mathrm{~s}$ & time between measurements: $1 \mathrm{sec}$ \\
\hline
\end{tabular}

For conversion of fluorescence intensity to concentration, calibration curves were constructed on each plate with a repeater pipette using DMSO solutions of the product 3 , dummy quencher $\mathbf{4}$, and fluorophore $\mathbf{1}$. For low concentrations of ligand where absorbance of the ligands and copper complexes were negligible, the mixtures of 1, 3, and $\mathbf{4}$ were prepared to correspond to $0 \%-100 \%$ completion in steps of $10 \%$ (rows) or $20 \%$ (columns). Other than the absence of ligand and the use of unreactive quencher, these mixtures reproduced exactly the conditions of the reaction wells.

To control for absorbance of ligand when necessary (as in Figure S6 and S7), calibrations were performed for each reaction simultaneously on the same plate, such that each plate consisted of a reaction half (with each reaction in quadruplicate) and a calibration half. The calibration wells contained mixtures of all the reagents and products corresponding to $0 \%, 25 \%$, $50 \%$, and $100 \%$ completion. Calibration was thereby performed individually for each time point using the standard curve constructed from these four points and regression equations in Microsoft Excel. Spreadsheets that accomplish the regression and convert fluorescence values to concentration are available from the authors. This type of calibration is especially useful for high ligand concentrations, very strongly absorbing ligands, and longer reaction times.

Experiments were set up in microtiter plates using the amounts shown in Table S4, and the appropriate buffer for determination of rate vs. $\mathrm{pH}$. The ligands were dissolved in DMSO, except for 17, which was first dissolved in water and then diluted into DMSO. After the addition of sodium ascorbate, the reactions were inserted into the plate reader and mixed (programmed shaking for 15 seconds). The preparation time between the addition of ascorbate and the start of data collection was approximately 3-4 minutes.

Figure S5 shows a typical example of the raw data thus obtained (fluorescence intensity vs. time). For each well showing a significant reaction rate, intensity values were converted to concentration by virtue of the calibration curve described above, and the data was then plotted in a simple second-order treatment, simplified by noting that the concentrations of 1 and 2 are identical throughout the reaction. Representative plots are shown in Figure S6. The data from 
four separate reactions (wells) were plotted together and the linear fit constructed to these points taken together.

Figure S5. Plots of fluorescence intensity vs. time for reactions in microtiter plate format.

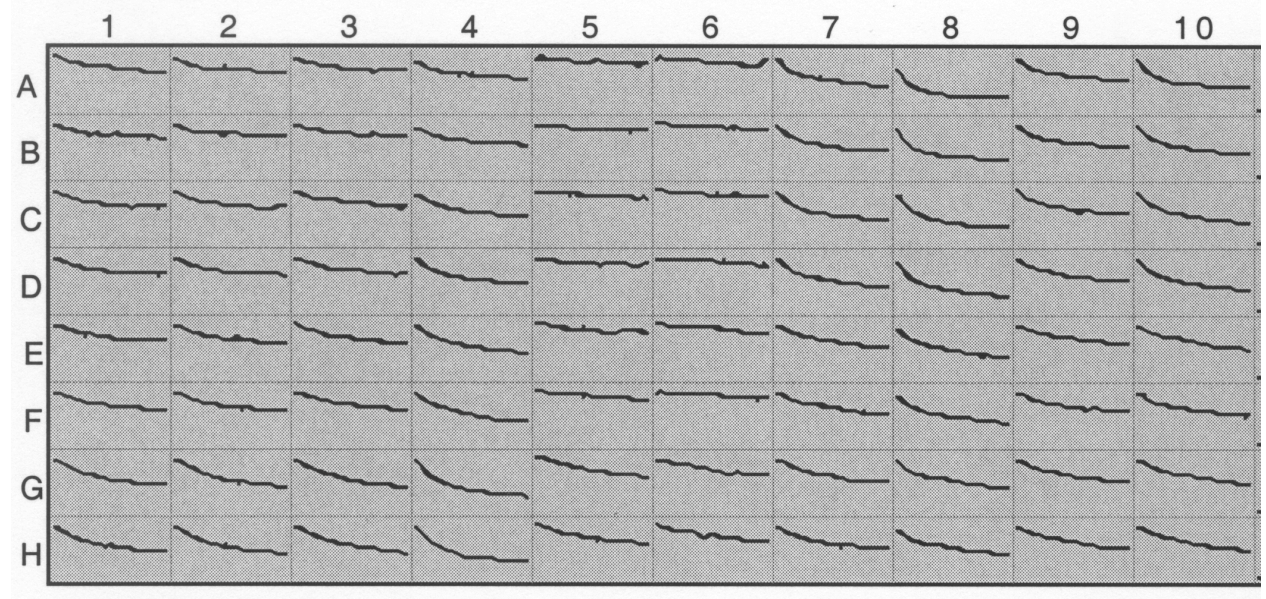

Figure S6. Example of second-order kinetics plots for bipyridine-type ligands from data obtained simultaneously in a 96-well microtiter plate $(\mathrm{pH} 8.0)$. Values for four runs of

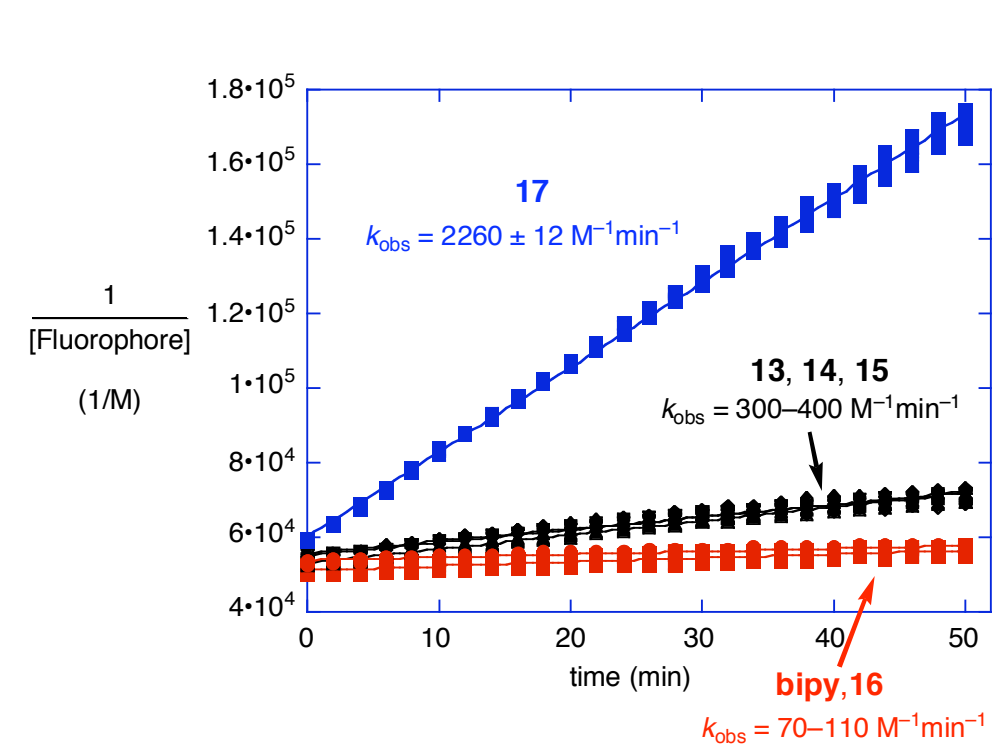
each ligand were overlayed and subjected to a single linear regression analysis of the combined points.

Table S4. Composition of reactions monitored quantitatively by fluorescence emission in microtiter plates for the example shown in Figure S6.

\begin{tabular}{|c|c|c|c|c|c|c|}
\hline & $\mathbf{1}$ & $\mathbf{2}$ or $\mathbf{4}$ & $\mathrm{CuSO}_{4}$ & Tris & lig in DMSO & Na ascorbate \\
\hline amount $(\mu \mathrm{L})$ & 50 & 50 & 50 & 50 & 25 & 50 \\
\hline stock conc $(\mathrm{mM})$ & 0.1 & 0.1 & varies & 500 & $0.5^{*}$ & 100 \\
\hline final conc. $(\mathrm{mM})$ & 0.018 & 0.018 & varies & 91 & 0.0455 & 18 \\
\hline
\end{tabular}

volume $=275 \mu \mathrm{L}, 45 \%$ DMSO, $55 \%$ buffer

* The concentration of the ligand stock solution was adjusted to create the other sets of reactions (at 9.2 $\mu \mathrm{M}$ and $23 \mu \mathrm{M}$ ligand, respectively).

The second-order rate constants thus obtained were plotted in Figure 2 of the manuscript and are shown in Table S5. Experimental errors were derived from the standard deviation of the slopes of the 
second order reciprocal plots of four pooled reaction datasets using Kaleidagraph software. The reported errors are the standard root mean squared values obtained from the linear regression.

Table S5. Second-order rates $\left(\mathrm{M}^{-1} \mathrm{~min}^{-1}\right)$ plotted in Figure 2. The set of data at $45 \mu \mathrm{M}$ ligands were not shown in the manuscript, but are plotted below.

\begin{tabular}{|c|c|c|c|c|c|c|c|c|c|}
\hline [Ligand] & Ligand & $\mathrm{pH} 7.5$ & pH 8.0 & $\mathrm{pH} 8.5$ & [Ligand] & Ligand & $\mathrm{pH} 7.5$ & $\mathrm{pH} 8.0$ & $\mathrm{pH} 8.5$ \\
\hline \multirow{9}{*}{$9.2 \mu \mathrm{M}$} & none & $65 \pm 10$ & $56 \pm 10$ & $138 \pm 20$ & \multirow{9}{*}{$23 \mu \mathrm{M}$} & none & $66 \pm 9$ & $58 \pm 18$ & $129 \pm 20$ \\
\hline & 13 & $132 \pm 8$ & $94 \pm 10$ & $210 \pm 13$ & & 13 & $223 \pm 26$ & $207 \pm 6$ & $323 \pm 22$ \\
\hline & 14 & $135 \pm 26$ & $142 \pm 9$ & $269 \pm 14$ & & 14 & $244 \pm 17$ & $308 \pm 26$ & $408 \pm 25$ \\
\hline & 15 & $120 \pm 12$ & $129 \pm 12$ & $229 \pm 9$ & & 15 & $245 \pm 16$ & $230 \pm 11$ & $411 \pm 29$ \\
\hline & 16 & $96 \pm 13$ & $79 \pm 6$ & $134 \pm 11$ & & 16 & $97 \pm 13$ & $90 \pm 7$ & $169 \pm 20$ \\
\hline & 17 & $271 \pm 13$ & $321 \pm 11$ & $776 \pm 64$ & & 17 & $761 \pm 24$ & $981 \pm 20$ & $1860 \pm 47$ \\
\hline & 11 & $333 \pm 36$ & $130 \pm 13$ & $163 \pm 11$ & & 11 & $556 \pm 24$ & $235 \pm 17$ & $228 \pm 11$ \\
\hline & 21 & $497 \pm 24$ & $270 \pm 23$ & $260 \pm 19$ & & 21 & $640 \pm 28$ & $334 \pm 21$ & $310 \pm 24$ \\
\hline & 22 & $423 \pm 16$ & $186 \pm 8$ & $233 \pm 15$ & & 22 & $650 \pm 39$ & $296 \pm 25$ & $247 \pm 26$ \\
\hline \multirow{6}{*}{$45 \mu \mathrm{M}$} & bipyridine & & $107 \pm 8$ & $218 \pm 4$ & & & & & \\
\hline & 13 & & $320 \pm 8$ & $414 \pm 7$ & & & & & \\
\hline & 14 & & $374 \pm 6$ & $632 \pm 6$ & & & & & \\
\hline & 15 & & $340 \pm 4$ & $595 \pm 8$ & & & & & \\
\hline & $\begin{array}{l}16 \\
17\end{array}$ & & $\begin{array}{c}80 \pm 5 \\
2260+12\end{array}$ & $\begin{array}{c}497 \pm 10 \\
3680+16\end{array}$ & & & & & \\
\hline & & & $\angle 200 \pm 12$ & $3680 \pm 10$ & & & & & \\
\hline
\end{tabular}

Complete Plot of Table S5.
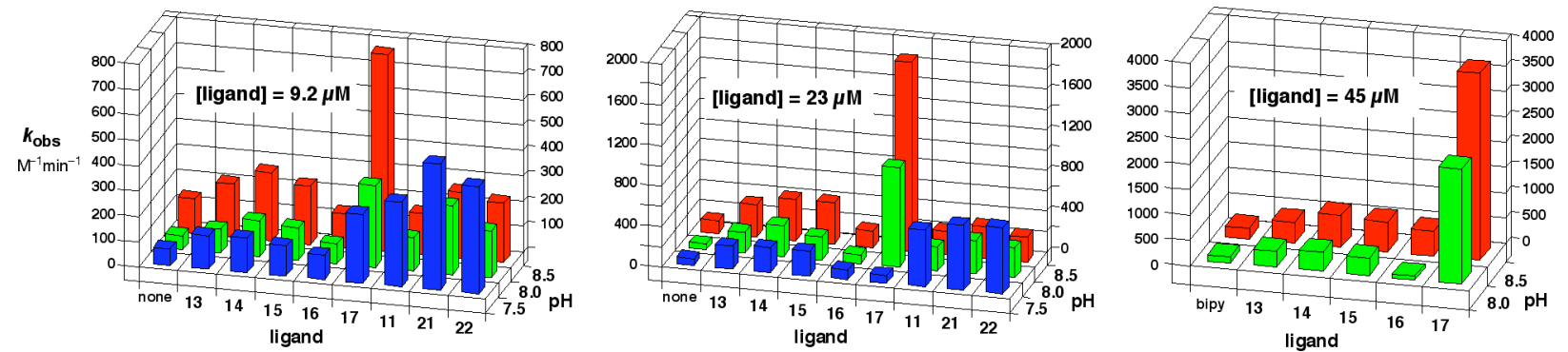

The question naturally arises of the magnitude of the rate acceleration in the presence of ligand. That ligand acceleration is substantial was made obvious by the observation that copper(I) alone at 4-25 $\mu \mathrm{M}$ (the concentration range of the copper-ligand mixtures) gave no discernable reaction. It was necessary to boost the concentration of $\mathrm{Cu}$ in the absence of ligand in order to see any reaction between azide and alkyne at the micromolar concentrations used for these substrates. Ligands were then added at increasing concentrations to give a series of reactions proceeding at increasing rates. To avoid reactions too fast to measure, as well as to minimize inhibition by excess ligand, relatively low concentrations of ligands were used relative to [Cu]. Since we have not established the rate dependence in copper under conditions in which the concentration of copper ions greatly exceeds that of the ligand, we cannot with confidence extract quantitative estimates of the magnitude of ligand acceleration from these data. If one assumes the reactions are first order in copper, then the rate accelerations in the presence of ligands range up to approximately 300 -fold. If the reaction is second order in copper (as measured for the $\mathrm{Cu} \cdot 17$ system without excess $\mathrm{Cu}$ ), then the rate accelerations on a per-Cu basis are calculated to reach levels of 10,000 . 


\section{Investigations of the catalyst.}

UV-visible titration of $\mathrm{Cu}(\mathrm{I})$ with ligand 17 showed the formation of a dark brown complex with a 2:1 ligand:copper stoichiometry. The composition of the active species was probed by measuring catalyst activity in the above fashion as a function of the 17:Cu ratio at $\mathrm{pH} 8$ (Figure S7). The measurement of reaction rate as a function of the concentration of the 2:1 17:Cu complex (Figure S8) showed a clean second-order dependence.

Figure S7. Second order rate constants for the first 20 minutes of reaction measured by fluorescence quenching kinetics in microtiter plate format for mixtures of $\mathbf{1 7}$ and $\mathrm{CuSO}_{4}$ at the concentrations indicated in Table S6.

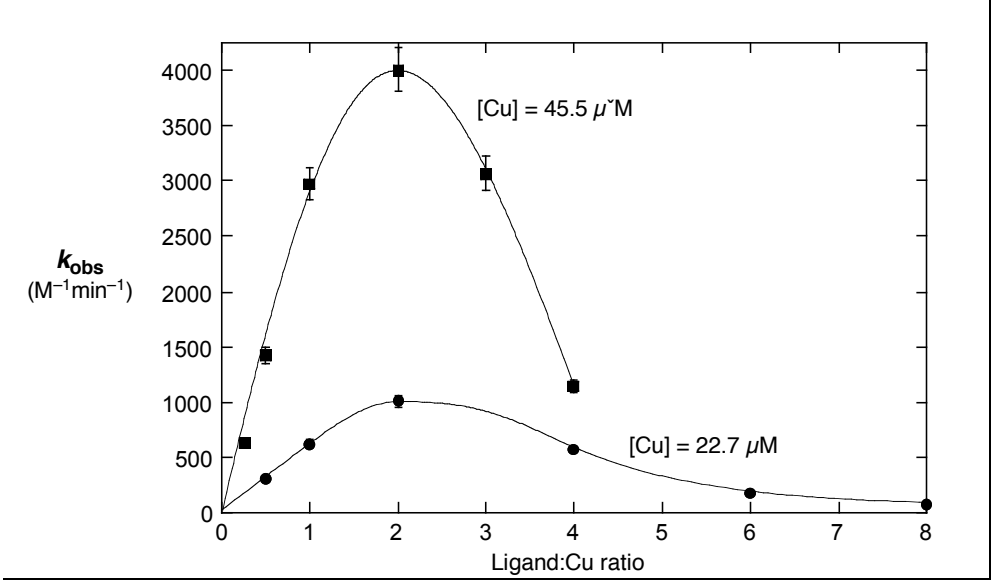

Table S6. Composition of reactions shown in Figure S7.

\begin{tabular}{|c|c|c|c|c|c|c|}
\hline & $\mathbf{1}$ & $\mathbf{2}$ or $\mathbf{4}$ & $\mathrm{CuSO}_{4}$ & Tris & $\mathbf{1 7}$ & Na ascorbate \\
\hline amount $(\mu \mathrm{L})$ & 50 & 50 & 50 & 50 & 25 & 50 \\
\hline stock conc $(\mathrm{mM})$ & 0.1 & 0.1 & 0.25 & 500 & $1^{*}$ & 100 \\
\hline final conc. $(\mathrm{mM})$ & 0.018 & 0.018 & 0.045 & 91 & 0.091 & 18 \\
\hline
\end{tabular}

volume $=275 \mu \mathrm{L}, 36 \%$ DMSO, 64\% buffer

* The concentration of the ligand stock solution was adjusted to create the other sets of reactions.

Figure S8. Determination of rate order in $\mathrm{Cu}(\mathbf{1 7})_{2}$ complex. Secondorder rate constants $\left(k_{\mathrm{obs}}, \mathrm{M}^{-1} \mathrm{~min}^{-1}\right)$ were measured as above for the concentrations of reagents indicated in Table S7. Red and blue data points are from two independent sets of reactions; each set was composed of four reactions in the same microtiter plate.

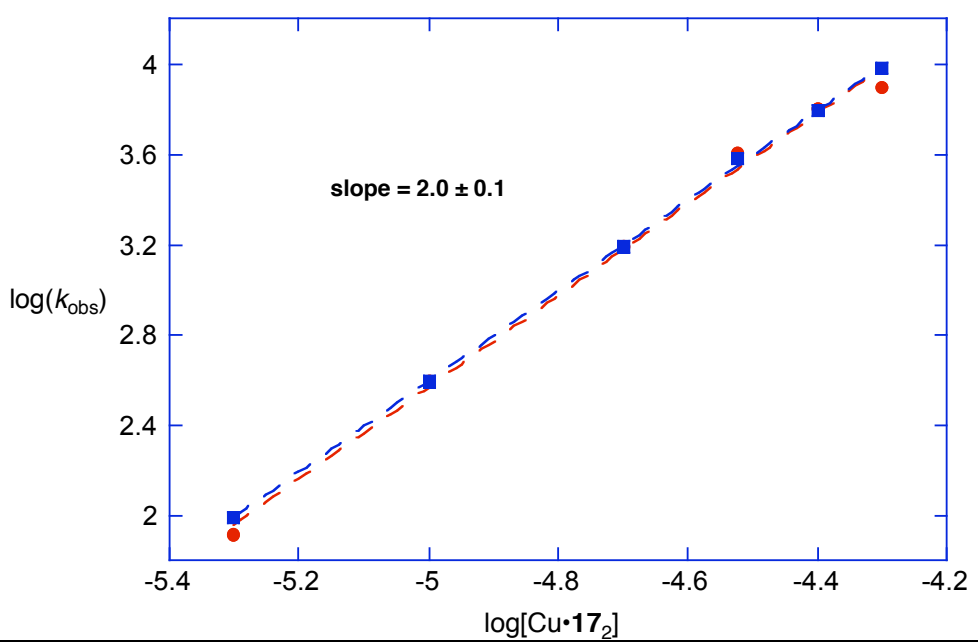


Table S7. Composition of reactions shown in Figure S8.

\begin{tabular}{|c|c|c|c|c|c|}
\hline & $\mathbf{1}$ & $\mathbf{2}$ or $\mathbf{4}$ & $\mathrm{Cu}(\mathbf{1 7})_{2}$ & Tris & Na ascorbate \\
\hline amount $(\mu \mathrm{L})$ & 50 & 50 & 50 & 50 & 50 \\
\hline stock conc $(\mathrm{mM})$ & 0.1 & 0.1 & varies $^{*}$ & 500 & 100 \\
\hline final conc. $(\mathrm{mM})$ & 0.020 & 0.020 & $0.005-0.050$ & 100 & 20 \\
\hline
\end{tabular}

* The concentration (of the preformed stock solutions containing 17 and $\mathrm{Cu}$ ) was adjusted to give the desired values.

\section{Preparative-scale reaction}

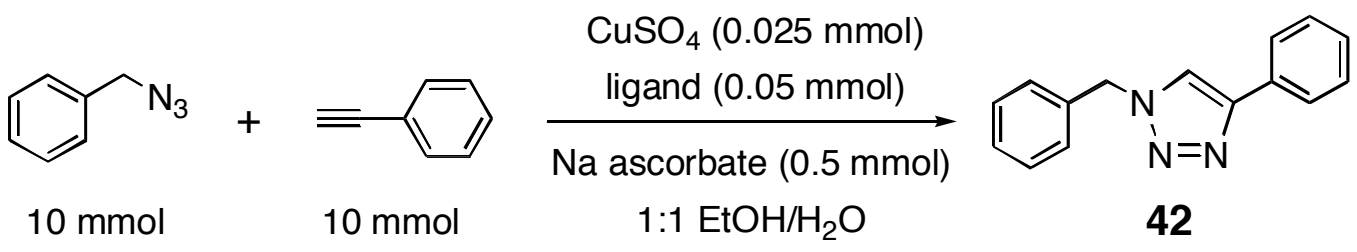

To a solution of benzyl azide and phenylacetylene in $95 \%$ ethanol was added an equal volume of water and 10-100 mM solution of ligand (11,13, or 17), a $1 \mathrm{M}$ solution of sodium ascorbate, followed by a $25 \mathrm{mM}$ solution of copper sulfate. The total volume of the reaction was $100 \mathrm{~mL}$, and the final concentrations of reagents and catalyst were as shown above. The reaction progress at room temperature was monitored by TLC (3:1 hexanes:ethyl acetate). Complete reaction was achieved within 3-4 hours in the presence of $0.25 \mathrm{~mol} \%$ copper(I). Over 1-3 days, needles of the product (42) were observed to crystallize from successful reaction mixtures in pure form, in yields greater than $85 \%$. No precautions, other than keeping the reaction vessel capped, were made to exclude oxygen. However, it was found that vigorous stirring of reactions open to air promoted the oxidation of the copper and compromised the reaction.

The triazole products derived from reactions involving 13 and 17 was found to be $\mathbf{4 2}$, and not its 1,5-regioisomer, by comparison with an authentic sample and as previously reported for the ligand-free and $\mathrm{Cu} \cdot 11$ systems. ${ }^{2}$ There is no reason to believe that the regioselectivity of the process changes with any ligand system tested to date.

2. (a) Rostovtsev, V. V.; Green, L. G.; Fokin, V. V.; Sharpless, K. B. Angew. Chem. Int. Ed. 2002, 41, 2596-2599. (b) Tornøe, C. W.; Christensen, C.; Meldal, M. J. Org. Chem. 2002, 67, 3057-3062. (c) Wang, Q.; Chan, T. R.; Hilgraf, R.; Fokin, V. V.; Sharpless, K. B.; Finn, M. G. J. Am. Chem. Soc. 2003, 125, 3192-3193. 